\title{
BMJ Open A Norwegian prospective study of preterm mother-infant interactions at 6 and 18 months and the impact of maternal mental health problems, pregnancy and birth complications
}

\author{
Aud R Misund, Stein Bråten, Per Nerdrum, Are Hugo Pripp, Trond H Diseth
}

To cite: Misund AR, Bråten S, Nerdrum P, et al. A Norwegian prospective study of preterm mother-infant interactions at 6 and 18 months and the impact of maternal mental health problems, pregnancy and birth complications. BMJ Open 2016;6:e009699. doi:10.1136/bmjopen-2015009699

- Prepublication history for this paper is available online. To view these files please visit the journal online (http://dx.doi.org/10.1136/ bmjopen-2015-009699).

Received 12 August 2015 Revised 12 January 2016 Accepted 1 March 2016

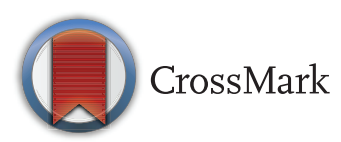

Faculty of Health Sciences, Department of Medicine, University College of Oslo and Akershus, Institute of Clinical Medicine, University of Oslo, Oslo, Norway

Correspondence to Dr Aud R Misund; aud.misund@hioa.no

\section{ABSTRACT}

Objective: Pregnancy, birth and health complications, maternal mental health problems following preterm birth and their possible impact on early mother-infant interaction at 6 and 18 months corrected age (CA) were explored. Predictors of mother-infant interaction at 18 months CA were identified.

Design and methods: This prospective longitudinal and observational study included 33 preterm motherinfant $(<33$ gestational age $(\mathrm{GA}))$ interactions at 6 and 18 months CA from a socioeconomic low-risk, middleclass sample. The Parent-Child Early Relational Assessment (PCERA) scale was used to assess the mother-infant interaction.

Results: 'Bleeding in pregnancy' predicted lower quality in preterm mother-infant interaction in 6 PCERA scales, while high 'maternal trait anxiety' predicted higher interactional quality in 2 PCERA scales and 'family size' predicted lower interactional quality in 1 PCERA scale at 18 months CA. Mothers with symptoms of posttraumatic stress reactions, general psychological distress and anxiety at 2 weeks postpartum (PP) showed significantly better outcome than mothers without symptoms in 6 PCERA subscales at 6 months CA and 2 PCERA subscales at 18 months CA.

Conclusions: Our study detected a correspondence between early pregnancy complications and lower quality of preterm mother-infant interaction, and an association between high levels of maternal mental health problems and better quality in preterm motherinfant interaction.

\section{INTRODUCTION}

Early parent-infant relationships that are well functioning seem to be critical to preterm children. Preterm children face severe risk of cognitive, emotional and behavioural disorders, ${ }^{1-8}$ and show more psychiatric symptoms in adolescence. ${ }^{9}$ Early parent-infant relationships that are well functioning seem to prevent and restore some of these difficulties in preterm children. ${ }^{10}{ }^{11}$

\section{Strengths and limitations of this study}

- The longitudinal design, the high response rate and the use of well-validated psychometric instruments and interactional assessment tool are the strengths of this study.

- Fifty per cent of the attending women received psychological treatment during the study, and it is a limitation that the influence of the psychological treatment on our study results was not assessed.

- The present study describes a small preterm group and one should be cautious about generalising from this study.

Good quality of mother-child interactions have been reported to facilitate the infant's emotional, behavioural, cognitive and neurobehavioral development. ${ }^{12-17}$ The interactional quality is also found to be related to the child's physical health. ${ }^{18}{ }^{19}$ Compared with infants born at term, the preterm infants are likely to show vague signals that are difficult to read and respond to and are in need of extended care and support to gain self-regulation. ${ }^{20} 21$ These traits, as well as parent's psychiatric disease, are known as risk factors for good-quality parent-infant interactions. $^{22} 23$ Research detected significant higher mental health problems following preterm birth than term birth. ${ }^{24-26}$

The maternal stress reaction following preterm birth has been highlighted as a risk factor in preterm dyads in several studies. ${ }^{24-29}$ Postpartum (PP) depression has been identified as a predictor of interactional difficulties in term dyads ${ }^{30}$ and reported as a risk factor for difficulties in preterm mother-infant dyads. ${ }^{31}$ Only a limited number of studies, however, have explored the nature of mothers' mental health problems following preterm birth with psychometric tools, and 
their impact on mother-infant interaction. Several studies, however, have explored the post-term effect on maternal mental health. ${ }^{32-36}$ Blom et $a l^{36}$ interestingly reported that certain perinatal complications such as pre-eclampsia, hospitalisation, emergency caesarean and fetal distress predicted higher depression outcomes in a normal population sample. An unaddressed trauma reaction is known to predispose for post-traumatic stress disorder (PTSD) with long-term effects on mothers' mental health. The effect of mothers' PP PTSD on mother-infant interaction and infant's development is less explored. ${ }^{37}$ In addition, only a limited number of studies have explored the maternal post-traumatic stress responses (PTSR) following preterm birth, ${ }^{38-45}$ and their impact on mother-infant interactions. ${ }^{20} 4246$

The results from preterm mother-infant interaction research are contradictory. Different measurements and definitions being used, as well as the complexity of mother-infant interactional studies, may have contributed to these differences. Some studies have reported that preterm mothers showed more stimulating behaviour and were emotionally withdrawn, as well as non-synchronous in their interaction with the child, ${ }^{20} 21$ 47-52 and others have found no interactional differences between preterm and full-term dyads. ${ }^{20}{ }^{53-58}$ Korja $e t a{ }^{56}$ detected that caregivers' physical closeness with the infant was more important to interactional quality than infants' prematurity. Finally, it is interesting that several studies have shown that mothers are intensifying their efforts to be available and supportive to their premature babies' needs. ${ }^{59-64}$ Preterm birth is reported to influence the interaction between mother and infant. ${ }^{20495}$ The knowledge of risk factors that may affect preterm mother-infant interaction is limited. ${ }^{31}{ }^{66-68}$ The need for further exploration of the complexity of factors influencing the early mother-infant relationship long-term in preterm dyads seems essential. ${ }^{6} 69$

The first aim of our longitudinal study was to explore the associations between maternal mental health problems following preterm birth, pregnancy and birth complications and early preterm mother-infant interaction at 6 months corrected age (CA) (T2) and 18 months CA (T3). The second aim of the study was to identify predictors of early mother-infant interaction quality at T2 and T3.

To the best of our knowledge, these associations have not been explored in other studies. Psychometric tools and tentative psychiatric diagnosis (anxiety, depression and PTSR/PTSD) were used to assess maternal mental health problems following preterm birth.

It should be noted that this paper is an extension of our previous studies of short-term and long-term maternal mental health problems following preterm birth. ${ }^{44} 45$

\section{METHOD}

\section{Participants}

Data were collected in two periods: June 2005-January 2006 and October 2007-July 2008. The psychological responses of 29 consecutive mothers of 35 premature children born before 33rd week of pregnancy were assessed at a highly specialised neonatal intensive care unit (NICU) at Oslo University Hospital, Norway. Mothers of severely ill babies that the medical staff estimated to have poor chance of survival, and non-Norwegian speakers were not included. The participants stayed in NICU until they were discharged home. The parents could participate in the caring of the infant during hospitalisation. The data collection was performed as soon as the mothers were able to attend an interview following preterm childbirth: within 2 weeks PP (T0), median 11 days (4-30); within 2 weeks after hospitalisation (T1), median time PP 2.7 months (0.24.7 ); at the infant's 6 months CA (T2), median time PP 8.5 months (7.6-10.4); and at the infant's 18 months CA (T3), median time following birth 20.6 months (19.223.4). Data of mother-infant interaction were collected only at T2 and T3. Mothers of severely ill babies with uncertain survival and non-native speakers were not included (figure 1).

Semistructured interviews and standardised mental health screening questionnaires were used to collect data about sociodemographics, the pregnancy and birth, child's health status and mothers' mental health problems. Medical charts were used to double-check the data of child's health status, and pregnancy and birth. The studied sample was homogeneous regarding high scores on sociodemographic variables such as education, income and housing standard. Most mothers were giving first-time birth late in their 20 s or early 30 s. All lived with the child's father and none reported any relationship problems (table 1). The participating mothers' mental health problems following preterm birth have been assessed at T0, $\mathrm{T} 1, \mathrm{~T} 2$ and T3, and methods and results are described in detail in our earlier papers. ${ }^{44}{ }^{45}$ Maternal mental health problems were assessed at every time points (T0, T1, T2, T3) by standardised psychometric methods with wellestablished reliability and validity: Impact of Event Scale (IES) 15-item version, one of the key psychometric assessment methods in traumatic stress research; ${ }^{70} 71$ the General Health Questionnaire (GHQ) 30-item version, a widely used screening instrument for assessing the presence of distress, psychopathology and overall wellbeing, ${ }^{72}{ }^{73}$ and the State/Trait Anxiety Inventory $(\mathrm{STAI}-\mathrm{X} 1 / \mathrm{X} 2)^{74}$ is widely used to assess maternal anxiety. STAI-X1 measures state anxiety levels reflecting subjective feelings of tension, apprehension, nervousness and worry. STAI-X2 is a measure of trait anxiety that refers to individual differences in anxiety proneness, that is, in the tendency to see the world as dangerous and threatening, and the frequency with which anxiety states are experienced. Score above the threshold for identifying a psychiatric case is referred to as a case score.

On the basis of all the information available in a clinical perusal of the psychometric self-report IES, GHQ and STAI of each of the 29 preterm mothers, and blinded to the physical and sociodemographic 
Figure 1 Inclusion and exclusion of mothers of 34 mothers with 40 infants assessed for preterm-born babies. eligibility

5 mothers with 5 infants refused to participate

*4 mothers out of lack of energy or mental capacity or lack of time. * 1 mother refused to be videotaped

2 mothers with 2 infants refused to participate at $\mathrm{T} 1$

*1 mother started to work

* 1 mother and infant were transferred to another Hospital

29 mothers with 35 infants included at 2 weeks postpartum (T0) and examined for maternal mental health problems.

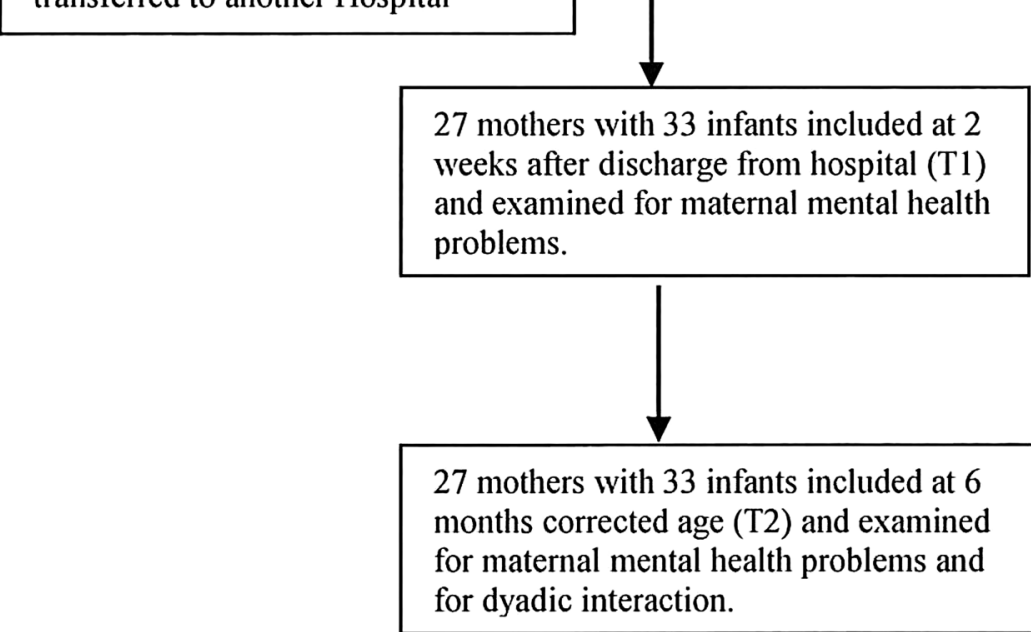

1 mother with 1 infant refused to participate at $\mathrm{T} 3$ due to her working load

characteristics of the mothers and their children, a tentative clinical diagnosis was made where appropriate based on the clinical descriptions and diagnostic guidelines in the International Classification of Diseases, 10th edition (ICD-10) classification of mental and behavioural disorders, and was assessed by a psychiatrist (last author).

A prevalence of maternal PTSR/PTSD 2 weeks PP (T0) of 52\% and maternal PTSD at 18 months CA (T3) of $23 \%$ was revealed. On the other hand, depression was detected among $24 \%$ of the mothers 2 weeks PP and among $8 \%$ of the mothers at T3. Anxiety decreased from $7 \%$ at 2 weeks PP to 0 at T3.

Fourteen of the mothers received psychological support at the hospital during their infants' NICU stay. Eleven of these mothers were referred for further psychological treatment after discharge from the hospital. 
Table 1 Sociodemographic, physical characteristics and mental health variables in mothers giving preterm birth and their children at 2 weeks postpartum (T0)

\begin{tabular}{|c|c|}
\hline Mothers & $\mathrm{N}=29$ \\
\hline Age; mean (SD) & $33.7(4.3)$ \\
\hline Education >12 years; $n$ (\%) & 26 (89.7) \\
\hline Single parent; $n(\%)$ & $0(0)$ \\
\hline Unemployed; n (\%) & $4(13.8)$ \\
\hline Previous psychological treatment; $\mathrm{n}(\%)$ & $8(27.6)$ \\
\hline Chronic illness; $n$ (\%) & $2(6.9)$ \\
\hline Total number of children; median (quartile low, upper) & $2(1,2)$ \\
\hline Previous pregnancies; median (quartile low, upper) & $1(0,2)$ \\
\hline Previous childbirths; median (quartile low, upper) & $0(0,1)$ \\
\hline First-time mothers; $n(\%)$ & $18(62.1)$ \\
\hline IVF* pregnancy; n (\%) & $8(27.6)$ \\
\hline Bleeding in pregnancy; $n(\%)$ & $19(65.5)$ \\
\hline Pre-eclampsia; $n$ (\%) & 4 (14.3) \\
\hline Caesarean; n (\%) & $17(58.6)$ \\
\hline \multicolumn{2}{|l|}{ Mental health variables $†$} \\
\hline IES total (0-75); median (quartile low, upper) & $18(11,30)$ \\
\hline IES case score $>18 ; n(\%)$ & $13(44.8)$ \\
\hline GHQ Likert score (0-90); n (\%) & $40(15.4)$ \\
\hline GHQ case $(0-30): n(\%)$ & $12.8(7.5)$ \\
\hline GHQ case score >5; n (\%) & 23 (79.3) \\
\hline STAI-X1 (0-40); mean (SD) & $21.5(2.8)$ \\
\hline STAI-X1 case score >19; $n(\%)$ & $20(69)$ \\
\hline STAI-X2 (0-80); mean (SD) & $44.0(4)$ \\
\hline STAI-X2 case score >39; n (\%) & 27 (93.1) \\
\hline PTSR tentative clinical diagnosis; $n$ (\%) & $15(51.7)$ \\
\hline Children & $n=35$ \\
\hline Girl; n (\%) & 17 (48.6) \\
\hline Boy; n (\%) & $18(51.4)$ \\
\hline Twinł; n (\%) & $14(40)$ \\
\hline \multicolumn{2}{|l|}{ Gestational age (weeks) } \\
\hline Median (range) & $29(24-32)$ \\
\hline Mean (SD) & $28.5(2.6)$ \\
\hline \multicolumn{2}{|l|}{ Birth weight (g) } \\
\hline Median (range) & $1185(623-2030)$ \\
\hline Mean (SD) & $1222(423)$ \\
\hline Apgar score at $1 \mathrm{~min}$; mean (SD) & $6,3(2.3)$ \\
\hline Apgar score at 5 min; mean (SD) & $7.6(2.0)$ \\
\hline Apgar score at 10 min; mean (SD) & $8.3(1.0)$ \\
\hline Oxygen supply>28 days; $n(\%)$ & $19(54)$ \\
\hline IVH§; n (\%) & $7(20.0)$ \\
\hline
\end{tabular}

*In vitro fertilisation (IVF)/assisted fertilisation.

tThe Impact of Event Scale (IES) 15-item version with scoring range from 0 (not at all) to 5 (very much), the General Health Questionnaire (GHQ) 30-item Likert scores with weights 0-1-2-3 and case scores with weights 0-0-1-1, the Spielberger State/Trait Anxiety Inventory (STAl-X1/X2) 10-item/20-item version with scoring range 1-2-3-4. The STAl-X1 10-item version was constructed since STAl-X1 12-item and 20 -item versions had been used and only 10 items overlapped. Tentative clinical diagnosis: post-traumatic stress responses (PTSR). $\ddagger T w o$ of the children registered as twins were raised as singletons because their twin sibling were stillborn.

§Intraventricular haemorrhage (IVH) grade 1-4 following birth.

Altogether, 20 mothers that met the criteria of clinical diagnoses were referred for adequate psychological treatments such as psychotherapy, psychopharmacology treatment and mother-infant interactional treatment. Five of the mothers refused the referral for psychological treatment, and only one of them filled the criteria for a tentative clinical diagnosis (PTSD/depression) at T3. The prevalence of pregnancy and birth complications and maternal mental health problems following preterm birth are reported in earlier papers. ${ }^{44} 45$
Data collected at 2 weeks PP (T0) about sociodemographics, physical complications and maternal mental health problems following preterm birth are presented in table 1.

\section{Measures}

Mother-infant interaction in a free-play situation was video recorded at 6 and 18 months CA. According to Clark (1985), by 6 months of age, dyadic mutuality and dyadic regulatory processes are perceptible, while at 
18 months, the infant's own communication skills are easier to identify in interaction. ${ }^{75}$ The interaction situation was recorded in a consultation room at the psychiatric clinic for children and families situated in the same building as the hospital the children were born in, except for four video recordings at 18 months CA that were recorded in their homes. The recordings were performed when child was awakened and interested in a play session with mother. Recordings were stopped and performed later when child became too distressed or sleepy to play. A therapist (first author) instructed the mothers about the procedure. For the video recording, the mother and the infant were placed on a soft mat with age-appropriate toys. Instructions given by the investigators to the mother prior to the video recording were: 'This is a free-play time with your child. You can use the toys, or you can play without the toys. Try to play or be with your infant as you usually would be'. Video recordings were obtained from all mother-infant pairs.

The recordings were $5 \mathrm{~min}$ long. The mother-infant interaction in the free-play situation was analysed using the Parent-Child Early Relational Assessment (PCERA) method. ${ }^{75}$ The PCERA is developed to assess affective and behavioural aspects that the parent and infant bring into the interaction, ${ }^{75}$ and the validity of the free-play situation has been established. ${ }^{76} 77$ Video recordings allow thorough analysis of the interactions several times and in short and slow sections that can identify areas of strength and of concern in the mother-infant interplay. The PCERA consists of 29 parental items, 28 infant items and 8 dyadic items. The assessment rates the frequency, duration and intensity of the infant's, parent's and dyad's behaviour. The parental items comprise the parent's positive and negative affect, expressed attitude towards the infant, sensitivity and contingent response to the infant's cues, mirroring the infant's feeling, capacity to structure, behavioural involvement and parental style. The infant items comprise expressed positive and negative affect and characteristic mood, behaviour/adaptive abilities, activity level and communication skills. The dyadic items comprise affective quality of interaction and mutuality of interaction.

All items were rated on a five-point 'Likert' scale. The scores 1 and 2 describe an area of concern, the score 3 describes an area of some concern and the scores 4 and 5 describe an area of strength. A trained coder made the assessment. The coder was unaware of the infant's background and clinical status. Additionally, to estimate the inter-rater reliability from the study data, $20 \%$ of all assessments were double-scored by another trained coder. The study data were assessed by calculating the mean of the agreement percentage of the raters' overall agreement. Agreement equal or above $80 \%$ is considered good, $50-80 \%$ is considered moderate and lower than $50 \%$ is considered poor. The mean of inter-rater agreements was $80.3 \%$ in 6 months $\mathrm{CA}$ and $81 \%$ in 18 months CA.
The PCERA items were organised into eight scales according to Clark, ${ }^{75}$ before the data analysis: 'maternal positive affective involvement PS1', 'maternal negative affect and behaviour PS2', 'maternal intrusiveness PS3', 'infant positive affect PS4', 'infant quality of play PS5', 'infant dysregulation PS6', 'dyadic mutuality and reciprocity PS7' and 'dyadic disorganization and tension PS8'. PCERA high scores (4-5) always indicate positive affect and behaviour or lack of negative affect and behaviour. Cronbach's $\alpha$ coefficients for calculating the internal consistency of PCERA subscales in our study were satisfactory and were $0.95,0.86,0.86,0.90,0.87$, $0.85,0.80,0.86$ for PS1-PS8 at 6 months CA (T2), and $0.89,0.81,0.82,0.92,0.89,0.75,0.73,0.79$ for PS1-PS8 at 18 months CA (T3).

The PCERA scale has been used in several studies to explore the quality of preterm mother-infant interactions. $^{31}{ }^{78-82}$

\section{Statistical methods}

Continuous variables are presented as means (SD) or if skewed, as median and range. Categorical variables are given as proportions and percentages. Paired-sample $t$ test was used for comparison of the PCERA mean scores at T2 and T3. Differences in the quality of motherinfant interactions measured by the PCERA scales were explored with independent sample t test. As grouping variable, we used mothers' case scores above threshold for identifying psychiatric symptoms $(0=$ no, $1=y e s)$ in IES, GHQ, STAI and the tentative diagnostic assessments at four time points: 2 weeks PP (T0), 2 weeks after hospitalisation (T1), 2 months CA (T2) and 18 months CA (T3) (figure 2A, B). A more detailed description of mothers' case scores in IES, GHQ, STAI and the tentative diagnostic assessments is available in our earlier papers. ${ }^{44} 45$

The association between variables at $\mathrm{T} 3$ was assessed using Pearson's correlation coefficient (table 2).

Stepwise regression analysis with a forward selection method was used to identify possible predictors of the PCERA results at T3 (table 3). At most, three variables at T3 with the strongest bivariate associations above 0.3 were included in the multivariable linear regression model; PS1 (STAI-X2 case, STAI-X2 sum, GHQ Likert), PS2 (bleeding in pregnancy, GHQ case, GHQ Likert), PS3 (STAI-X2 case, bleeding in pregnancy, parity/ STAI-X2 sum), PS4 (bleeding in pregnancy, GHQ case), PS5 (bleeding in pregnancy, Apgar $5 \mathrm{~min}$ ), PS6 (family size, acute caesarean, bleeding in pregnancy), PS7 (bleeding in pregnancy, GHQ case, STAI-X2 case) and PS8 (bleeding in pregnancy, GHQ case, cerebral haemorrhage $(\mathrm{CH})$ <grade 3). A careful check of the model assumptions, including an investigation of residual plots, did not reveal any violation of the assumptions. All analyses were performed using SPSS V.20. Two-sided statistical tests were applied and a 5\% statistical significance level was chosen. 
A PCERA PS1 subscale (Parental Positive Affective Involvement and Verbalization)

$\square$ Case $\square$ No Case

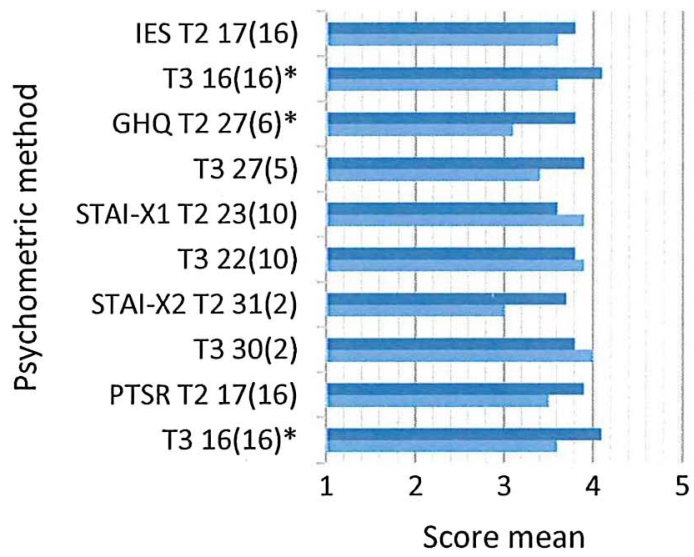

\section{PCERA PS3 subscale (Parental Intrusiveness, Intensitivity and Inconsistency)}

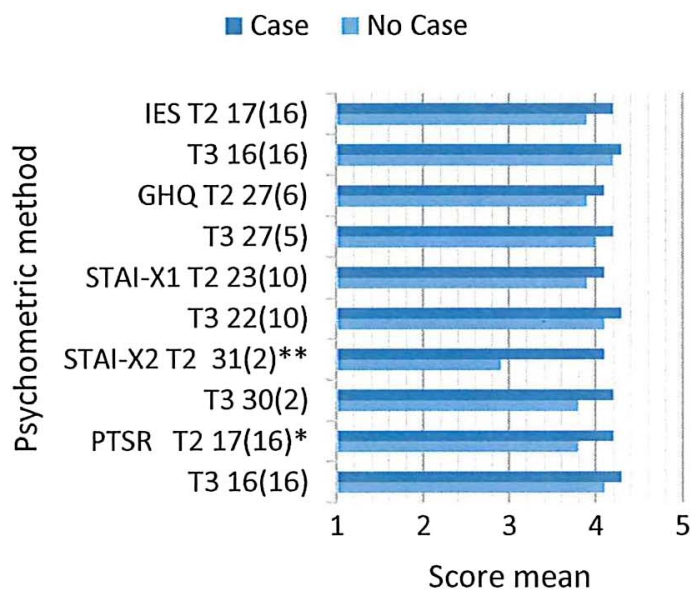

PCERA PS2 subscale (Parental

Negative Affective Involvement and Verbalization)

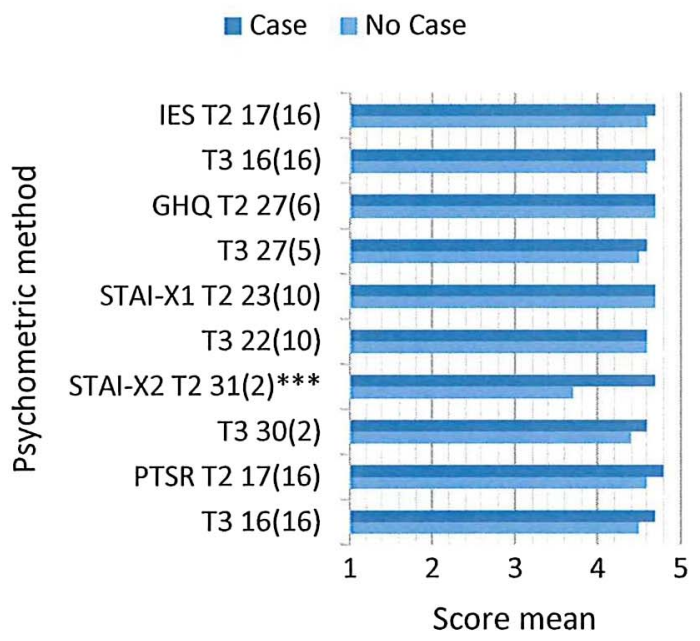

\section{PCERA PS4 subscale (Infant Positive Affect, Communicative and Social Skills)}

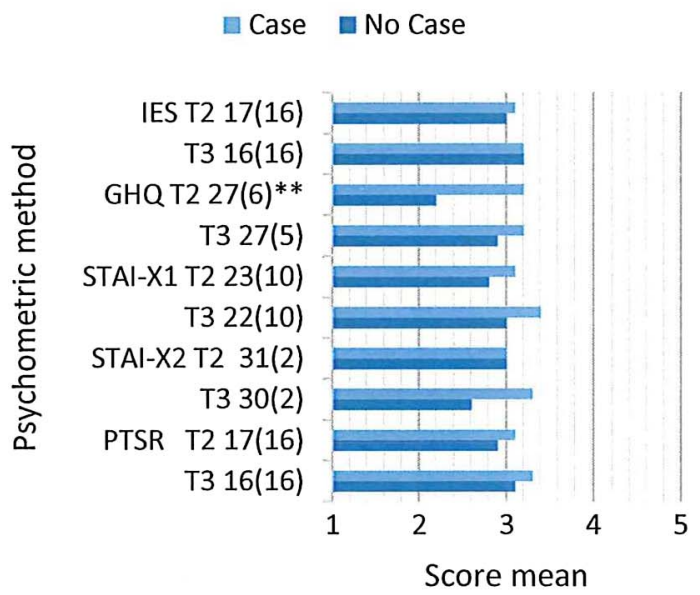

Figure 2 (A) Group differences in mother-infant interaction quality at 6 (T2) and 18 (T3) months corrected age for mothers with and without psychometric case scores above threshold for identifying psychiatric case at 2 weeks postpartum. The mother-infant interaction quality was measured by mean scores in the PCERA subscale; PS1-PS4. (B) Group differences in mother-infant interaction quality at 6 (T2) and 18 (T3) months corrected age for mothers with and without psychometric case scores above threshold for identifying psychiatric case at 2 weeks postpartum. The mother-infant interaction quality was measured by mean scores in the PCERA subscale; PS5-PS8.(GHQ, general health questionnaire; IES, impact of event scale; PTSR, post-traumatic stress responses; STAI, state/trait anxiety inventory).

Ethics

Written informed consent was obtained from participants prior to the study start. The study protocol was approved in 5 May 2005 and 19 April 2007 by the National Committee for Research Ethics (S-05068 and S-07096b) and 1 April 2005 and 12 March 2007 by the Data Inspectorate (12360 and 07/1088). The study protocol was carried out in accordance with the Declaration of Helsinki.
For ethical reasons, the mothers that reported mental health problems and had case scores above the threshold for identifying psychiatric symptoms in IES, GHQ and STAI were assessed and referred for adequate psychological treatment. In this study, we looked for mental health problems in mothers at four points from the time of birth to 2 years PP. A no referral procedure could have caused unnecessary suffering for mothers and children. 
Figure 2 Continued. Play and Relatedness)

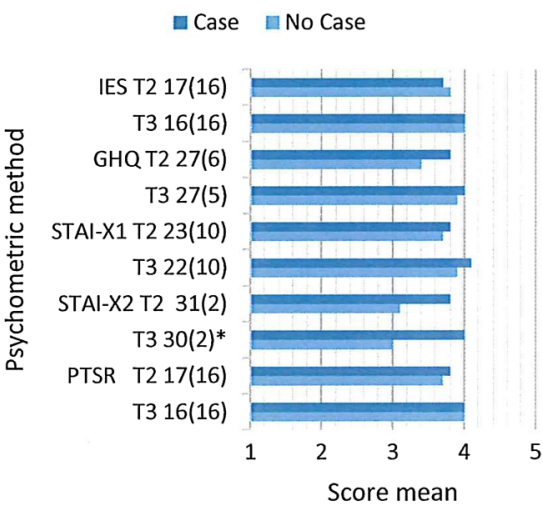

PCERA PS7 subscale (Dyadic Mutuality and Reciprocity)

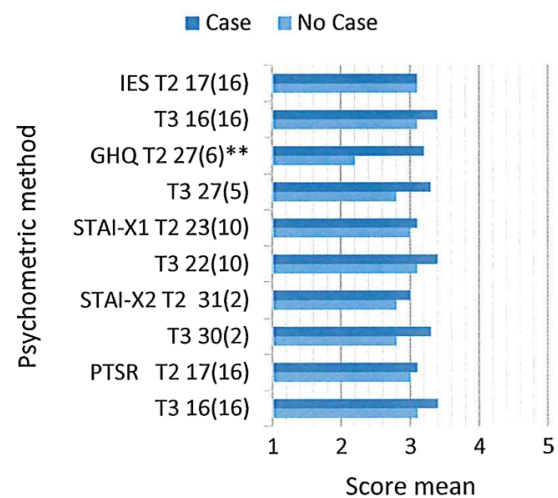

PCERA PS6 subscale (Infant Dysregulation and Irritability)

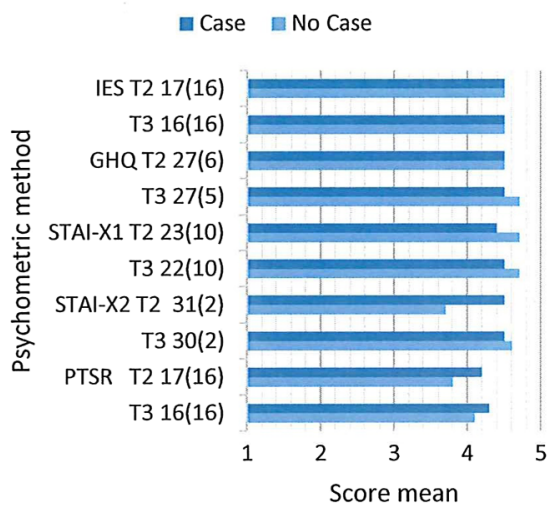

PCERA PS8 subscale (Dyadic Disorganization and Tension)

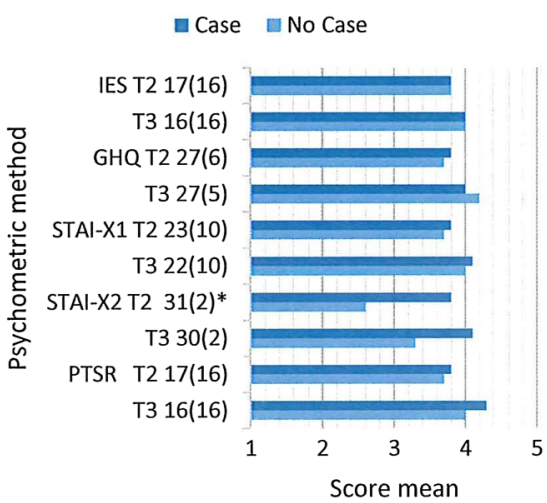

Scores 1-2=Area of concern, Score 3=Area of some concern, Scores 4-5=Area of strength

The number of mothers with (without) clinical case scores in IES (Impact of event scale), GHQ (General Health Questionnaire), STAI (State/trait anxiety inventory) and tentative PTSR (Post-traumatic stress responses) diagnosis at T0 is reported in the diagram next to the psychometric methods.

*Significant difference at the .05 level (2-tailed).

**Significant difference at the .01 level (2-tailed).

*** Significant difference at the .001 level (2-tailed).

\section{RESULTS}

Associations between maternal mental health problems following preterm birth, pregnancy and birth complications and early preterm mother-infant interaction at 6 months CA (T2) and 18 months CA (T3)

The paired-sample $t$ test of the results of the PCERA showed no significant difference for the PCERA mean scores from 6 months to 18 months corrected age (CA). For that reason, the presented results from correlation and regression analysis are based only on the mean scores from 18 months CA. The results of the PCERA revealed mean scores in three of the scales in the area of moderate concern and five scales in the area of no concern. The results of the PCERA are presented in table 2.
Group differences in mother-infant interaction quality at T2 and T3 for mothers with and without psychometric case scores at T0, T1, T2 and T3

The results of the independent-sample t test showed significant group differences at T2 and T3 between the mothers with case scores above the threshold for identifying a psychiatric case compared to mothers without case scores; in IES that measure symptoms of post-traumatic stress following preterm childbirth, in GHQ which measure symptoms of general psychological distress, and in tentative PTSR diagnosis at T0 (figure 2A, B). Mothers identified with case scores of GHQ at T3 also showed significant better results at the 0.05 level (two-tailed)* in two PCERA scales at T3; PS7 dyadic mutuality and reciprocity $\left(\mathrm{N} 0 / \mathrm{N} 1=24 / 8\right.$, mean $\left.3.1 / 3.7^{*}\right)$, and PS8 dyadic 


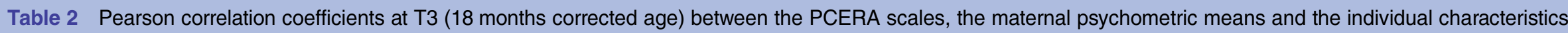
of the mothers and infants $(n=32)$

\begin{tabular}{|c|c|c|c|c|c|c|c|c|}
\hline & $\begin{array}{l}\text { PCERA } \\
\text { PS1 } \\
\text { Maternal } \\
\text { positive affective } \\
\text { involvement }\end{array}$ & $\begin{array}{l}\text { PCERA } \\
\text { PS2 } \\
\text { Maternal } \\
\text { negative affect } \\
\text { and behaviour }\end{array}$ & $\begin{array}{l}\text { PCERA PS3 } \\
\text { Maternal } \\
\text { intrusiveness, } \\
\text { insensitivity and } \\
\text { inconsistency }\end{array}$ & $\begin{array}{l}\text { PCERA PS4 } \\
\text { Infant positive } \\
\text { affect, } \\
\text { communicative } \\
\text { and social skills }\end{array}$ & $\begin{array}{l}\text { PCERA PS5 } \\
\text { Infant quality } \\
\text { of play, } \\
\text { interest and } \\
\text { attention }\end{array}$ & $\begin{array}{l}\text { PCERA } \\
\text { PS6 } \\
\text { Infant } \\
\text { dysregulation } \\
\text { and irritability }\end{array}$ & $\begin{array}{l}\text { PCERA } \\
\text { PS7 } \\
\text { Dyadic } \\
\text { mutuality and } \\
\text { reciprocity }\end{array}$ & $\begin{array}{l}\text { PCERA } \\
\text { PS8 } \\
\text { Dyadic } \\
\text { disorganisation } \\
\text { and tension }\end{array}$ \\
\hline $\begin{array}{l}\text { GHQ Likert sum } \\
\text { score }\end{array}$ & $0.39^{*}$ & $0.37^{*}$ & $0.35^{*}$ & 0.16 & 0.12 & 0.05 & 0.30 & 0.28 \\
\hline $\begin{array}{l}\text { GHQ case sum } \\
\text { score }\end{array}$ & $0.36^{*}$ & $0.36^{*}$ & 0.06 & 0.12 & 0.07 & 0.17 & 0.26 & 0.31 \\
\hline $\mathrm{GHQ}$ case $>5$ & 0.26 & $0.40^{*}$ & 0.30 & 0.33 & 0.29 & 0.21 & $0.41^{*}$ & $0.43^{*}$ \\
\hline $\begin{array}{l}\text { STAI-X2 sum } \\
\text { score }\end{array}$ & $0.46 \dagger$ & 0.21 & $0.39^{*}$ & 0.09 & -0.03 & 0.08 & 0.25 & 0.19 \\
\hline STAI-X2 case $>39$ & $0.48^{*}$ & $0.36^{*}$ & $0.57 \dagger$ & 0.19 & 0.06 & 0.07 & 0.32 & 0.32 \\
\hline Parity & 0.07 & 0.18 & $0.39^{*}$ & 0.24 & 0.10 & 0.01 & 0.31 & 0.33 \\
\hline $\mathrm{CH}<$ grade $3 \ddagger$ & -0.21 & -0.28 & $-0.35^{\star}$ & -0.20 & -0.23 & -0.15 & -0.30 & -0.35 \\
\hline Apgar at $5 \mathrm{~min}$ & -0.01 & 0.09 & 0.20 & 0.22 & $0.35^{\star}$ & -0.12 & 0.18 & 0.19 \\
\hline $\begin{array}{l}\text { Bleeding in } \\
\text { pregnancy }\end{array}$ & -0.22 & $-0.45 \dagger$ & $-0.56 \dagger$ & $-0.53 \dagger$ & $-0.55 \dagger$ & -0.33 & $-0.46 \dagger$ & $-0.52 \dagger$ \\
\hline Family size§ & -0.09 & -0.12 & 0.07 & -0.02 & -0.16 & $-0.45^{*}$ & 0.01 & 0.00 \\
\hline Acute caesarean & 0.14 & 0.14 & 0.13 & 0.01 & 0.03 & $0.39^{*}$ & 0.07 & 0.22 \\
\hline $\begin{array}{l}\text { Mean/range } \\
\text { (min-max) }\end{array}$ & $\begin{array}{l}3.8 / 2.5 \\
(2.3-4.8)\end{array}$ & $\begin{array}{l}4.6 / 1.6 \\
(3.4-5.0)\end{array}$ & $\begin{array}{l}4.2 / 2.0 \\
(3.0-5.0)\end{array}$ & $\begin{array}{l}3.2 / 3.0 \\
(1.9-4.9)\end{array}$ & $\begin{array}{l}4.0 / 2.2 \\
(2.7-4.9)\end{array}$ & $\begin{array}{l}4.5 / 1.3 \\
(3.7-5.0)\end{array}$ & $\begin{array}{l}3.3 / 2.8 \\
(2.0-4.8)\end{array}$ & $\begin{array}{l}4.0 / 2.0 \\
(3.0-5.0)\end{array}$ \\
\hline
\end{tabular}

Mean values, range scores and minimum and maximum scores for PCERA subscales are reported in the last row of this table.

${ }^{*}$ Correlation is significant at the 0.05 level (two-tailed).
tCorrelation is significant at the 0.01 level (two-tailed).

†Correlation is significant at the 0.01 level (two-tailed).
${ }^{\ddagger} \mathrm{CH}<$ grade 3 refers to cerebral haemorrhage grade 1 or 2 closely after birth.

$\S$ Family size refers to the number of children in the family.

IRates 1 and 2 in PCERA subscale; 'area of concern'. Rate 3 in PCERA subscale; 'area of moderate concern'. Rates 4 and 5 in PCERA subscale; 'area of no concern'.

$\mathrm{CH}$, cerebral haemorrhage; GHQ, general health questionnaire; PCERA, parent-child early relational assessment; STAl, state/trait anxiety inventory. 
disorganisation and tension ( $\mathrm{N} 0 / \mathrm{N} 1=24 / 8$, mean 3.9 / $\left.4.4^{*}\right)$. Unexpectedly, the mothers with case scores (1=yes) at T0 showed significantly better quality in mother-infant interaction in six (T2) and two (T3) subscales of the PCERA than mothers with no $(0=$ no $)$ case scores (figure 2A, B). Tentative depression or anxiety diagnosis $(0=$ no, $1=y e s)$ as a grouping variable showed no significant group differences regarding the quality of the mother-infant interaction.

\section{Associations between maternal mental health problems and mother-infant interactional quality at T3}

In the bivariate correlation analyses, we revealed a positive correlation between better interactional quality measured by PCERA and higher levels of maternal mental health problems measured by psychometric means at T3. High levels of maternal psychological distress measured by GHQ Likert and case scores correlated with high levels of PCERA scores in three scales, and maternal psychological distress measured by GHQ case sum scores correlated with two scales. High levels of maternal trait anxiety measured by STAI-X2 sum scores were associated with high levels of PCERA scores in two scales, and maternal trait anxiety measured by STAI-X2 case scores correlated with three scales (table 2).

\section{Associations between pregnancy/birth complications, maternal variables and mother-infant interactional quality at T3}

The strongest correlations were inverse and found between a pregnancy complication 'bleeding in pregnancy' and the following six PCERA scales: 'maternal negative affect and behaviour (PS2), maternal intrusiveness, intensity and inconsistency (PS3), infant positive affect, communicative and social skills (PS4), infant quality of play, interest and attention (PS5), dyadic mutuality and reciprocity (PS7) and dyadic disorganization and tension (PS8)'.

Two infant complications following birth were correlated with two of the PCERA scales. Infant health scores at the infant's 'Apgar scores at 5 min postpartum' correlated positively with the 'infant quality of play, interest and attention (PS5)' scale. Infant stroke by 'intraventricular haemorrhage grade 1 or 2 (IVH)' closely following birth correlated inversely with the 'maternal negative affect and behaviour (PS2)' scale (table 2).

Three maternal variables correlated with two of the PCERA scales. Parity (number of previous births with child survival) and the scale 'maternal intrusiveness, intensity and inconsistency (PS3)' were positively correlated. Family size (number of children in the family) and the 'infant dysregulation and irritability (PS6)' scale inversely correlated. 'Acute caesarean' correlated positively with high scores on the same scale.

Associations between exposure variables, for example, in vitro fertilisation (IVF) treatment, prenatal and postnatal maternal health problems and pregnancy and birth/postnatal complications, were not significant.

\section{Predictors of mother-infant interactional quality at T3}

In the multivariable linear regression analyses, we revealed that the pregnancy complication variable 'bleeding in pregnancy' was a significant predictor $(p<0.01)$ of lower scores in preterm mother-infant interaction in six of the PCERA domains, including both of the dyadic scales (table 3). Trait anxiety (STAI-X2) case and sum score are significant predictors for higher quality in preterm mother-infant interaction in the 'maternal positive affect domain (PS1)' $(\mathrm{p}<0.01)$ and in the 'maternal intrusiveness domain (PS3)' ( $p<0.05)$, consecutively. Higher 'number of children in the family' predicts lower interaction quality in the 'infant dysregulation and irritability (PS6)' scale $(\mathrm{p}<0.05)$. Adjusted $\mathrm{R}^{2}$ showed that the predictors explain from $17 \%$ to $39 \%$ of the variance in different PCERA scales.

\section{DISCUSSION}

The study revealed significant associations between pregnancy and birth complications, maternal PP mental health and the quality of preterm mother-infant interaction. The most surprising results in our study were the detection of (1) 'bleeding in pregnancy' as a predictor of lower quality in preterm mother-infant interaction in six of eight PCERA scales and (2) the association between high levels of maternal mental health problems and better mother-infant interactional quality.

The predictor 'bleeding in pregnancy' is interesting. No other study has, to the best of our knowledge, revealed a physical complication in pregnancy that predicts a possible weaker quality of the mother-infant interaction following preterm birth. With reference to our previous papers, 'bleeding in pregnancy', was detected as a predictor of low levels in maternal mental health symptoms, while a sudden complication later in pregnancy 'pre-eclampsia', predicted high levels of maternal mental health problems following preterm birth. ${ }^{44} 45$ As 'bleeding in pregnancy' usually occurs before 22 weeks of pregnancy, it may be experienced as an early warning sign for possible pregnancy complications by the mother. A possible hypothesis may be that early complications in pregnancy and complications late in pregnancy influence the mother differently in the way she relates to her unborn child and how her transition into motherhood alternates. Early bleeding in pregnancy could leave the mother-to-be with the impression that her child is at risk and when preterm birth becomes reality, it may confirm her fear of loss. Given such an enduring threatening impression, the mother can be expected to be anxious and alert, preventing her from relaxing and taking pleasure in the mother-infant interaction, and rather initiating negative affect and intrusiveness which may also entail dyadic disorganisation and tension.

On the other hand, the mother without prior early warning signs is likely to have been quite 'undisturbed' in her transition process to prepare for motherhood 
Table 3 Significant results of the multivariable regression analyses with the selected independent variables to predict mother-child interaction following preterm birth at T3 (18 months corrected age)

\begin{tabular}{|c|c|c|c|c|c|c|}
\hline & Predicting variable & B & Cl & $\boldsymbol{\beta}$ & p Value & \\
\hline \multicolumn{7}{|l|}{ PCERA subscales } \\
\hline $\begin{array}{l}\text { PS1 (maternal positive } \\
\text { affective involvement) }\end{array}$ & STAI-X2 case & 0.53 & (0.17 to 0.89$)$ & 0.48 & 0.005 & 0.21 \\
\hline $\begin{array}{l}\text { PS2 (maternal negative affect } \\
\text { and behaviour) }\end{array}$ & Bleeding in pregnancy & -0.21 & $(-0.37$ to -0.06$)$ & -0.45 & 0.009 & 0.18 \\
\hline PS3 (maternal intrusiveness) & $\begin{array}{l}\text { Bleeding in pregnancy } \\
\text { STAI-X2 sum score }\end{array}$ & -0.290 .03 & $\begin{array}{l}(-0.45 \text { to }-0.13) \\
(0.01 \text { to } 06)\end{array}$ & -0.530 .35 & $\begin{array}{l}0.001 \\
0.017\end{array}$ & 0.39 \\
\hline PS4 (infant positive affect) & Bleeding in pregnancy & -0.43 & $(-0.68$ to -0.17$)$ & -0.53 & 0.002 & 0.26 \\
\hline PS5 (infant quality of play) & Bleeding in pregnancy & -0.35 & $(-0.56$ to -0.15$)$ & -0.55 & 0.001 & 0.27 \\
\hline PS6 (infant dysregulation) & Family size & -0.24 & $(-0.42$ to -0.06$)$ & -0.45 & 0.011 & 0.17 \\
\hline $\begin{array}{l}\text { PS7 (dyadic mutuality and } \\
\text { reciprocity) }\end{array}$ & Bleeding in pregnancy & -0.33 & $(-0.56$ to -0.09$)$ & -0.33 & 0.008 & 0.21 \\
\hline $\begin{array}{l}\text { PS8 (dyadic disorganisation } \\
\text { and tension) }\end{array}$ & Bleeding in pregnancy & -0.32 & $(-0.51$ to -0.12$)$ & -0.52 & 0.002 & 0.25 \\
\hline
\end{tabular}

Unstandardised (B) and standardised ( $\beta$ ) regression coefficients $(n=32)$.

PCERA subscales were used as dependent variables (at most, three variables with strongest bivariate association above 0.3 were used as independent variables).

PS1 (STAI-X2 case, STAI-X2 sum score, GHQ Likert sum score), PS2 (bleeding in pregnancy, GHQ case, GHQ Likert sum score), PS3

(STAI-X2 case, bleeding in pregnancy, parity/STAl-X2 sum score), PS4 (bleeding in pregnancy), PS5 (bleeding in pregnancy, Apgar at 5 min), PS6 (family size, acute caesarean), PS7 (bleeding in pregnancy, GHQ case) and PS8 (bleeding in pregnancy, GHQ case).

PCERA, parent-child early relational assessment; STAI, state/trait anxiety inventory.

until later in her pregnancy. 'Pre-eclampsia' and a sudden preterm birth induce a serious situation for mother and child, and both may risk non-survival. When mother experiences hope for infant survival, we may assume that a prior 'undisturbed' transition process into motherhood is likely to increase her efforts to attain the very best mother-infant interaction.

Attachment theory supports our hypothesis that loss or possible loss can be seen as serious threats to attachment. ${ }^{83}$ A growing number of research show that mothers' attachment pattern is associated with the mother-infant interaction, ${ }^{84}{ }^{85}$ and an assessment of mothers' attachment pattern would possibly have given a valuable perspective to our results.

Unexpectedly, our results showed that high levels of maternal mental health problems following preterm birth were significantly associated with better quality in preterm mother-infant interaction. In regression analysis, we found that high levels of maternal anxiety measured by STAI-X2 predicted better mother-infant interaction in two PCERA scales at T3. In our previous studies, we found an association between STAI-X2 and general psychological distress outcomes following preterm birth, ${ }^{44} 45$ and another study revealed an association between STAI-X2 and post-traumatic stress outcomes following term birth. ${ }^{86}$ With reference to these studies, we may suggest that there is a significant association between high levels of mental health problems following preterm birth and better quality in two PCERA scales at T3. In the independent-sample t test, we also found that mothers with symptoms of post-traumatic stress, general psychological distress and anxiety at 2 weeks PP (T0) showed significantly better quality in mother-infant interaction on six PCERA scales at 6 months (T2) and on two PCERA scales at 18 months corrected age (T3).

It is theoretically interesting that our results imply that high levels of maternal mental distress improve the preterm mother-infant interaction. At the first glance, this result seems to contradict the well-known connection between high levels of maternal depression and high-risk mother-infant interactions. ${ }^{31}{ }^{87-89}$ It should be noted that we found quite low prevalence of depression among the mothers participating in this study. ${ }^{44} 45$ Instead, we found high levels of post-traumatic stress reactions. PTSD following childbirth is acknowledged by several researchers to be potentially different from PTSD following other traumatic incidences. ${ }^{37}$ The culturally positive connotation of giving birth, the mother-child connection, the transition from pregnancy to giving birth and the formal care setting the birth incident takes place in are all matters that may have an impact on PTSD following preterm birth. Several studies have reported that many people experience positive psychological growth after struggling with trauma. ${ }^{90} 91$ Maternal post-traumatic stress reaction following preterm birth is characterised by a prior physical trauma where survival of the mother and the baby may be at risk. Is it possible that maternal post-traumatic stress reactions following preterm birth helps the mother to focus her attention towards her premature baby's wellbeing? Our findings may imply that the post-traumatic stress response activates and helps the mother cope over time with a tremendously stressful situation, and furthermore helps her stimulate the prematurely born child's healthy development. Several studies support our 
view. $^{60-62}{ }^{64}$ However, other studies that have explored maternal mental health problems following preterm birth and preterm mother-child interactions have reported results that contradict with our findings. ${ }^{42} 508192$ Studies that have used the PCERA scale in studying preterm dyads, however, did not find depression to be a significant predictor of PCERA outcome at 6,12 , or 16 months CA. $^{31} 79$ The sociodemographic variable 'family size' predicted low interactional quality in one of the PCERA scales. In our study, the mothers with preterm babies that had siblings showed significantly lower scores in the 'infant dysregulation scale (PS6)' in the PCERA. Our result is supported by two studies in the 1970s and 1980s that found the preterm infant's birth order to affect the mother-child interaction. ${ }^{93} 94$ An explanation for their results was the mother's divided attention between the infant and other siblings.

\section{Strength/limitations}

The results from a small and explorative study have low statistical power and low external validity, ${ }^{95}$ and one should be cautious about generalising from the study. In most studies, there is also a possibility that confounding variables are not included in the analysis that should have been. In our study, such factors could have been assessment of mothers' attachment patterns, the effect of psychological assessment and referral procedure and an assessment of the comforting conditions for motherinfant interactions in the hospital. However, our study results may still be of value for future research that will systematically explore the complexity of factors influencing early preterm mother-infant interaction in a broader sense.

The participants in this study were included consecutively and both single and multiple births were included, thus minimising selection bias. Our sample was homogeneous in socioeconomic background (SES). However, the mothers had higher educational attainments, greater age and higher socioeconomic status, higher number of twins and higher rate of previous psychological treatment than would be found in a typical population of mothers who deliver preterm in our country. In this sample, we found no indication of significant differences in parental challenges between participants with singletons or twins that needed to be controlled for. Besides high prevalence of earlier psychological treatment among the mothers in our sample, no other collected data indicated that mental distress had impact on their psychosocial function in everyday life before the actual preterm birth incident. Regarding research on quality of the preterm mother-infant interaction, it has been considered that risk factors other than preterm birth itself have been sources of bias in many studies. ${ }^{20} 4896$ In our study, we have controlled for highrisk socioeconomic backgrounds.

It is a limitation that the video procedure of PCERA could not be followed for the four dyads that were recorded in their homes and not in the clinic, as were the others. On the other hand, these dyads would not have participated if the recordings were not made in their homes. It is a limitation that inter-rater reliability was not checked for tentative clinical diagnosis. The prediction model used in this study needs further validation by future studies.

\section{CONCLUSIONS}

Our study detected a correspondence between early pregnancy complications and lower quality of preterm mother-infant interaction, and an association between high levels of maternal mental health problems and better quality in preterm mother-infant interaction.

Early intervention programmes should be considered for mothers who give preterm birth to support motherinfant interaction.

Acknowledgements The authors would like to thank the families that participated in the study, the staff of the maternity ward at the neonatal intensive care unit at the National Hospital, Oslo and Sari Ahlqvist-Björkroth who coded and Tanja Lipasti who recoded the PCERA data. In particular, we want to thank the parents who participated in the study.

Contributors ARM initiated the study, collected, and organised the data. ARM and AHP performed the statistical analyses. ARM, PN, SB, AHP and THD wrote the article.

Funding This work was supported by the Centre for Child and Adolescent Mental Health, Eastern and Southern Norway and the University College of Oslo and Akershus.

Competing interests None declared.

Ethics approval The National Committee for Research Ethics and the Data Inspectorate.

Provenance and peer review Not commissioned; externally peer reviewed.

Data sharing statement The full data set is available from the corresponding author ARM (aud.misund@hioa.no).

Open Access This is an Open Access article distributed in accordance with the Creative Commons Attribution Non Commercial (CC BY-NC 4.0) license, which permits others to distribute, remix, adapt, build upon this work noncommercially, and license their derivative works on different terms, provided the original work is properly cited and the use is non-commercial. See: http:// creativecommons.org/licenses/by-nc/4.0/

\section{REFERENCES}

1. Martinussen M, Flanders DW, Fischl B, et al. Segmental brain volumes and cognitive and perceptual correlates in 15-year-old adolescents with low birth weight. J Pediatr 2009;155:848-53.e1.

2. Limperopoulos C, Bassan H, Gauvreau K, et al. Does cerebellar injury in premature infants contribute to the high prevalence of long-term cognitive, learning, and behavioral disability in survivors? Pediatrics 2007;120:584-93.

3. de Kieviet JF, Zoetebier L, van Elburg RM, et al. Brain development of very preterm and very low-birthweight children in childhood and adolescence: a meta-analysis. Dev Med Child Neurol 2012;54:313-23.

4. Aarnoudse-Moens CSH, Weisglas-Kuperus N, van Goudoever JB, et al. Meta-analysis of neurobehavioral outcomes in very preterm and/or very low birth weight children. Pediatrics 2009;124:717-28.

5. Johnson S. Cognitive and behavioural outcomes following very preterm birth. Semin Fetal Neonatal Med 2007;12:363-73.

6. Bhutta A, Cleves MA, Casey $\mathrm{PH}$, et al. Cognitive and behavioral outcomes of school-aged children who were born preterm: a meta-analysis. JAMA 2002;288:728-37.

7. Lowe J, Woodward B, Papile L. Emotional regulation and its impact on development in extremely low birth weight infants. J Dev Behav Pediatr 2005;26:209-13. 
8. Hayes B, Sharif F. Behavioural and emotional outcome of very low birth weight infants--literature review. J Matern Fetal Neonatal Med 2009;22:849-56.

9. Indredavik MS, Vik T, Heyerdahl S, et al. Psychiatric symptoms in low birth weight adolescents, assessed by screening questionnaires. Eur Child Adolesc Psychiatry 2005;14:226-36.

10. Nordhov SM, Rønning JA, Ulvund SE, et al. Early intervention improves behavioral outcomes for preterm infants: randomized controlled trial. Pediatrics 2012;129:e9-16.

11. Nordhov SM, Ronning JA, Dahl LB, et al. Early intervention improves cognitive outcomes for preterm infants: randomized controlled trial. Pediatrics, 2010;126:e1088-94.

12. Cohen SE, Beckwith L. Preterm infant interaction with the caregiver in the first year of life and competence at age two. Child Dev 1979;50:767-76.

13. Crnic KA, Ragozin AS, Greenberg MT, et al. Social interaction and developmental competence of preterm and full-term infants during the first year of life. Child Dev 1983;54:1199-210.

14. Bekckwith L, Rodning C. Dyadic processes between mothers and preterm infants: development at ages 2 and 5 years. Infant Ment Health J 1996;17:322-33.

15. Milgrom J, Westley DT, Gemmill AW. The mediating role of materna responsiveness in some longer term effects of postnatal depression on infant development. Infant Behav Dev 2004;27:443-54.

16. Dennis T. Emotional self-regulation in preschoolers: the interplay of child approach reactivity, parenting, and control capacities. Dev Psychol 2006;42:84-97.

17. Goldsmith HH, Davidson, RJ. Disambiguating the components of emotion regulation. Child Dev 2004;75:361-5.

18. Mäntymaa M, Puura K, Luoma I, et al. Infant-mother interaction as a predictor of child's chronic health problems. Child Care Health Dev 2003;29:181-91.

19. Mäntymaa M, Puura K, Luoma I, et al. Early mother-infant interaction, parental mental health and symptoms of behavioral and emotional problems in toddlers. Infant Behav Dev 2004;27:134-49.

20. Muller-Nix C, Forcada-Guex M, Pierrehumbert B, et al. Prematurity, maternal stress and mother-child interactions. Early Hum Dev 2004;79:145-58

21. Forcada-Guex M, Pierrehumbert B, Borghini A, et al. Early dyadic patterns of mother-infant interactions and outcomes of prematurity at 18 months. Pediatrics 2006;118:e107-14.

22. Kvello Ø. Barn i risiko: skadelige omsorgssituasjoner. Oslo: Gyldendal akademisk. 2010. 442 s. : ill.

23. Goodman, $\mathrm{SH}$, Rouse $\mathrm{MH}$, Connell $\mathrm{AM}$, et al. Maternal depression and child psychopathology: a meta-analytic review. Clin Child Fam Psychol Rev 2011;14:1-27.

24. Kaaresen PI, Ronning JA, Ulvund SE, et al. A randomized, controlled trial of the effectiveness of an early-intervention program in reducing parenting stress after preterm birth. Pediatrics 2006;118: e9-19.

25. Singer LT, Salvator A, Guo S, et al. Maternal psychological distress and parenting stress after the birth of a very low-birth-weight infant. JAMA 1999;281:799-805.

26. Spear ML, Leef K, Epps S, et al. Family reactions during infants' hospitalization in the neonatal intensive care unit. Am J Perinatol 2002;19:205-14.

27. Hughes M, McCollum J, Sheftel D, et al. How parents cope with the experience of neonatal intensive care. Child Health Care 1994;23:1-14

28. Seideman RY, Watson MA, Corff KE, et al. Parent stress and coping in NICU and PICU. J Pediatr Nurs 1997;12:169-77.

29. Kaaresen PI, Rønning JA, Tunby J, et al. A randomized controlled trial of an early intervention program in low birth weight children: outcome at 2 years. Early Hum Dev 2008;84:201-9.

30. Murray L, Cooper PJ, Wilson A, et al. Controlled trial of the shortand long-term effect of psychological treatment of post-partum depression: 2 . Impact on the mother-child relationship and child outcome. Br J Psychiatry 2003;182:420-7.

31. Korja R, Savonlahti E, Ahlqvist-Björkroth S, et al. Maternal depression is associated with mother-infant interaction in preterm infants. Acta Paediatr 2008;97:724-30.

32. van Pampus MG, Wolf $\mathrm{H}$, Weijmar Schultz WC, et al. Posttraumatic stress disorder following preeclampsia and HELLP syndrome. $J$ Psychosom Obstet Gynecol 2004;25:183-7.

33. Rep A, Ganzevoort W, Bonsel GJ, et al. Psychosocial impact of early-onset hypertensive disorders and related complications in pregnancy. Am J Obstet Gynecol 2007;197:158.e1-6.

34. Skari $\mathrm{H}$, Malt UF, Bjornland $\mathrm{K}$, et al. Prenatal diagnosis of congenital malformations and parental psychological distress-a prospective longitudinal cohort study. Prenat Diagn 2006;26:1001-9.
35. Kaasen, A, Helbig A, Malt UF, et al. Acute maternal social dysfunction, health perception and psychological distress after ultrasonographic detection of a fetal structural anomaly. BJOG 2010;117:1127-38.

36. Blom EA, Jansen PW, Verhulst FC, et al. Perinatal complications increase the risk of postpartum depression. The Generation R Study BJOG 2010;117:1390-8.

37. Mckenzie-Mcharg, K, Ayers S, Ford E, et al. Post-traumatic stress disorder following childbirth: an update of current issues and recommendations for future research. J Reprod Infant Psychol 2015;33:219-37.

38. Kersting A, Dorsch $M$, Wesselmann U, et al. Maternal posttraumatic stress response after the birth of a very low-birth-weight infant. J Psychosom Res 2004;57:473-6.

39. Jotzo M, Schmitz B. Traumatisierung der Eltern durch die Frühgeburt des Kindes. Psychotraumatologie 2002;3:38.

40. Jotzo M, Poets CF. Helping parents cope with the trauma of premature birth: an evaluation of a trauma-preventive psychological intervention. Pediatrics 2005;115:915-19.

41. Binder WS, Zeltzer LK, Simmons CF, et al. The father in the hallway: posttraumatic stress reactions in fathers of NICU babies. Psychiatr Ann 2011;41:396-402.

42. Eutrope J, Thierry A, Lempp F, et al. Emotional reactions of mothers facing premature births: study of 100 mother-infant Dyads 32 gestational weeks. PLoS ONE 2014;9:e104093.

43. Ghorbani, M, Dolatian M, Shams J, et al. Factors associated with posttraumatic stress disorder and its coping styles in parents of preterm and full-term infants. Glob J Health Sci 2014;6:65-73.

44. Misund AR, Nerdrum P, Diseth TH. Mental Health in women experiencing preterm birth. BMC Pregnancy Childbirth 2014;14:263.

45. Misund AR, Nerdrum $P$, Bråten $S$, et al. Long-term risk of mental health problems in women experiencing preterm birth: a longitudinal study of 29 mothers. Ann Gen Psychiatry 2013;12:33.

46. Pierrehumbert B, Nicole A, Muller-Nix C, et al. Parenta post-traumatic reactions after premature birth: implications for sleeping and eating problems in the infant. Arch Dis Child FetalNeonatal Ed 2003;88:F400-4.

47. Goldberg S, Divitto B. Parenting children born preterm. In: Bornstein $\mathrm{MH}$, ed. Children and parenting. Handbook of parenting. 2nd edn.

Vol 1. USA: Lawrence Erlbaum Associates Inc, 2002

48. Gerner EM. Emotional interaction in a group of preterm infants at 3 and 6 months of corrected age. Infant Child Dev 1999;8:117-28.

49. Minde K, Perrotta M, Marton P. Maternal caretaking and play with full-term and premature infants. J Am Acad Child Psychiatry 1985;26:231-44.

50. Schmücker G, Brisch K-H, Köhntop B, et al. The influence of prematurity, maternal anxiety, and infants' neurobiological risk on mother-infant interactions. Infant Ment Health J 2005;26:423-41.

51. Feldman R, Eidelman Al. Neonatal state organization, neuromaturation, mother-infant interaction, and cognitive development in small-for-gestational-age premature infants. Pediatrics 2006;118:e869-78.

52. Feldman R, Eidelman Al. Maternal postpartum behavior and the emergence of infant-mother and infant-father synchrony in preterm and full-term infants: the role of neonatal vagal tone. Dev Psychobiol 2007;49:290-302.

53. Greenberg MT, Crnic KA. Longitudinal predictors of developmental status and social interaction in premature and full-term infants at age two. Child Dev 1988;59:554-70.

54. Schermann-Eizirik, L, Hagekull B, Bohlin G, et al. Interaction between mothers and infants born at risk during the first six months of corrected age. Acta Paediatr 1997;86:864-72.

55. Montirosso R, Borgatti R, Trojan S, et al. A comparison of dyadic interactions and coping with still-face in healthy pre-term and full-term infants. Br J Dev Psychol 2010;28:347-68.

56. Korja R, Maunu J, Kirjavainen J, et al. Mother-infant interaction is influenced by the amount of holding in preterm infants. Early Hum Dev 2008;84:257-67.

57. Crawford J. Mother-infant interaction in premature and full-term infants. Child Dev 1982;53:957-62.

58. Greene JG, Fox NA, Lewis M. The relationship between neonatal characteristics and three-month mother-infant interaction in high-risk infants. Child Dev 1983;54:1286-96.

59. Hoffenkamp, HN, Tooten A, Hall RA, et al. The impact of premature childbirth on parental bonding. Evol Psychol 2012;10:542.

60. Korja R, Latva R, Lehtonen $L$. The effects of preterm birth on mother-infant interaction and attachment during the infant's first two years. Acta Obstetr Gynecol Scand 2012;91:164-73.

61. Beckwith L, Cohen SE. Preterm birth: hazardous obstetrical and postnatal events as related to caregiver-infant behavior. Infant Behav Dev 1978;1:403-11. 
62. Leiderman P. Human mother-infant social bonding: is there a sensitive phase? In: Immelmann K, Barlow G, Petrinovich L, Main M eds. Behavioral development: the Bielefeld Interdisciplinary Project. Cambridge: Cambridge University Press, 1981:454- 68.

63. Myers BJ. Mother-infant bonding: the status of this critical-period hypothesis. Dev Rev 1984;4:240-74.

64. Wright B, Zucker R. Parental responses to competence and trauma in infants with reproductive casualty. J Abnorm Child Psychol 1980;8:385-95.

65. Beckwith L, Rodning C. Dyadic processes between mothers and preterm infants: development at ages 2 to 5 years. Infant Ment Health J 1996;17:322-33.

66. Feldman R, Eidelman Al, Sirota L, et al. Comparison of skin-to-skin (kangaroo) and traditional care: parenting outcomes and preterm infant development. Pediatrics 2002;110(Pt 1): 16-26.

67. Feldman, $R$, Weller A, Sirota $L$, et al. Testing a family intervention hypothesis: the contribution of mother-infant skin-to-skin contact (kangaroo care) to family interaction, proximity, and touch. J Fam Psychol 2003;17:94-107.

68. Field T. Attachment and separation in young children. Annu Rev Psychol 1996;47:541-61.

69. Saigal S. Follow-up of very low birthweight babies to adolescence. Semin Neonatol 2000;5:107-18.

70. Sundin EC, Horowitz MJ. Horowitz's Impact of Event Scale evaluation of 20 years of use. Psychosom Med 2003;65:870-6.

71. Horowitz MJ, Wilner N, Alvarez W. Impact of Event Scale: a measure of subjective stress. Psychosom Med 1979;41:209-18.

72. Goldberg D, Williams P. A user's guide to the general health questionnaire. London: Nfer-Nelson, 1991:129.

73. Malt U. The validity of the General Health Questionnaire in a sample of accidentally injured adults. Acta Psychiatr Scand Suppl 1989;80:103-12.

74. Spielberger CD, Goursch RL, Luschene RE. STAI manual for the state-trait anxiety inventory. Palo Alto, CA: Consulting Psychologists Press, 1970.

75. Clark R. The parent-child early relational assessment: instrument and manual. Madison: University of Wisconsin Medical School, Department of Psychiatry, 1985.

76. Clark R, Hyde JS, Essex MJ, et al. Length of maternity leave and quality of mother-infant interactions. Child Dev 1997;68:364-83.

77. Clark R The parent-child early relational assessment: a factorial validity study. Educ Psychol Meas 1999;59:821-46.

78. Korja R, Ahlqvist-Björkroth S, Savonlahti E, et al. Relations between maternal attachment representations and the quality of mother-infant interaction in preterm and full-term infants. Infant Behav Dev 2010;33: 330-6.

79. McManus B, Poehlmann J. Parent-child interaction, maternal depressive symptoms and preterm infant cognitive function. Infant Behav Dev 2012;35:489.
80. Schwichtenberg AJ, Anders TF, Vollbrecht M, et al. Daytime sleep and parenting interactions in infants born preterm. J Dev Behav Pediatr 2011;32:8-17.

81. Shah PE, Clements M, Poehlmann J. Maternal resolution of grief after preterm birth: implications for infant attachment security. Pediatrics 2011;127:284-92.

82. Poehlmann J, Schwichtenberg AJ, Shlafer RJ, et al. Emerging self-regulation in toddlers born preterm or low birth weight: differential susceptibility to parenting? Dev Psychopathol 2011;23:177-93.

83. Bowlby J. Attachment and Loss: Volume 1: Attachment (Vol. 79) Tavistock Institute of Human Relations: Basic Books, 1969.

84. Fonagy $\mathrm{P}$, Target $\mathrm{M}$. Bridging the transmission gap: an end to an important mystery of attachment research? Attac Hum Dev 2005;7:333-43.

85. Coppola G, Cassibba R, Costantini A. What can make the difference? Premature birth and maternal sensitivity at 3 months of age: the role of attachment organization, traumatic reaction and baby's medical risk. Infant Behav Dev 2007;30:679-84.

86. Czarnocka J, Slade P. Prevalence and predictors of post-traumatic stress symptoms following childbirth. Br J Clin Psychol 2000;39 (Pt 1):35-51

87. Downey G, Coyne JC. Children of depressed parents: an integrative review. Psychol Bull 1990;108:50.

88. Goodman SH, Gotlib IH. Risk for psychopathology in the children of depressed mothers: a developmental model for understanding mechanisms of transmission. Psychol Rev 1999;106:458.

89. Lovejoy MC, Graczyk PA, O'Hare E, et al. Maternal depression and parenting behavior: a meta-analytic review. Clin Psychol Rev 2000;20:561-92.

90. Tedeschi RG, Park CL, Calhoun LG. Posttraumatic growth: conceptual issues. In: Tedeschi RG, Park CL, Calhoun LG, eds. Posttraumatic growth: positive changes in the aftermath of crisis. Mahwah, NJ: Earlbaum, 1998:1-22.

91. Calhoun LG, Tedeschi RG. The foundation of posttraumatic growth: an expanded framework. In: Calhoun LG, Tedeschi RG, eds. Handbook of posttraumatic growth: research and practice. Mahwah, New York: Lawrence Erlbaum, 2006:2-23.

92. Feeley N, Gottlieb L, Zelkowitz P. Infant, mother, and contextual predictors of mother-very low birth weight infant interaction at 9 months of age. J Dev Behav Pediatr 2005;26:24-33.

93. Bendersky $M$, Lewis $M$. The impact of birth order on mother-infant interactions in preterm and sick infants. J Dev Behav Pediatr 1986;7:242-6.

94. Cohen SE, Beckwith L. Caregiving behaviors and early cognitive development as related to ordinal position in preterm infants. Child Dev 1977;48:152-7.

95. Kazdin AE. Research design in clinical psychology. 5th edn. Pearson New International Edition, 2013.

96. Wille DE. Relation of preterm birth with quality of infantmother attachment at one year. Infant Behav Dev 1991;14: 227-40. 